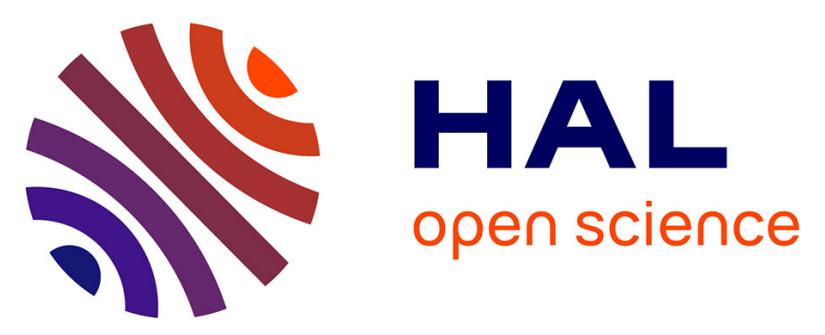

\title{
Removal of NAPL from columns by oxidation, sparging, surfactant and thermal treatment
}

Florie Jousse, Olivier Atteia, Patrick Höhener, Grégory Cohen

\section{To cite this version:}

Florie Jousse, Olivier Atteia, Patrick Höhener, Grégory Cohen. Removal of NAPL from columns by oxidation, sparging, surfactant and thermal treatment. Chemosphere, 2017, 188, pp.182-189. 10.1016/j.chemosphere.2017.08.163 . hal-01588249

\section{HAL Id: hal-01588249 \\ https://hal-amu.archives-ouvertes.fr/hal-01588249}

Submitted on 4 May 2018

HAL is a multi-disciplinary open access archive for the deposit and dissemination of scientific research documents, whether they are published or not. The documents may come from teaching and research institutions in France or abroad, or from public or private research centers.
L'archive ouverte pluridisciplinaire HAL, est destinée au dépôt et à la diffusion de documents scientifiques de niveau recherche, publiés ou non, émanant des établissements d'enseignement et de recherche français ou étrangers, des laboratoires publics ou privés. 


\title{
Removal of NAPL from columns by oxidation, sparging, surfactant and thermal treatment
}

\author{
F. Jousse ${ }^{\mathrm{a}}$, O. Atteia ${ }^{\mathrm{a}, \mathrm{b}, *}$, P. Höhener ${ }^{\mathrm{c}}$, G. Cohen ${ }^{\mathrm{a}, \mathrm{b}}$ \\ a Fondation Innovasol, 1 Allee Daguin, 33607, Pessac, France \\ ${ }^{\mathrm{b}}$ ENSEGID - EA 4592 Géoressources et Environnement, Institut Carnot Isifor, 1 Allee Daguin, 33607, Pessac, France \\ c Aix Marseille Univ, CNRS UMR 7376, Laboratoire Chimie Environnement, 3 place Victor Hugo, F-13331, Marseille, France
}

\section{A R T I C L E I N F O}

Article history:

Received 2 February 2017

Received in revised form 11 August 2017

Accepted 30 August 2017

Available online $\mathrm{xxx}$

Handling Editor: Hyunook Kim

Keywords

Remediation

Columns

Oxidant

Thermal

Surfactant

Sparging

\section{A B S T R A C T}

In this paper, four treatment techniques commonly applied to Volatile Organic Compounds (VOC) removal from soil are compared in column experiments with pure sand containing a residual Light Non-Aqueous Phase Liquid (L-NAPL) contamination. Oxidation is tested through the injection of Fenton reagent, with persulfate, and combined with sparging with the injection of ozone. Surfactant treatment was conducted at low flow rates with Tween ${ }^{\circledR} 80$. Sparging was conducted by air injection but at a low flow rate of $1 \mathrm{~mL} \mathrm{~min}^{-1}$. Finally several columns were thermally treated at a temperature of $80^{\circ} \mathrm{C}$. The results showed high removal $(>90 \%)$ for all techniques used, although only thermal treatment on BTEX (Benzene, Toluene, Ethylbenzene and Xylenes) reached $100 \%$ efficiency. The main limiting factors of each technique were: (i) for oxidation, the solubility of the substance limited the removal; (ii) for surfactant both the solubility in the surfactant and the type of surfactant are important; (iii) for sparging, the main factors are contaminant vapor pressure and porous media grain size; (iv) for thermal treatment, the limitation arises from the contaminant vapor pressure and the medium hydraulic conductivity. A comparison with literature data shows that the results are consistent with most of the studies conducted on one technique.

\section{Introduction}

Diesel fuel is commonly used for road and railways transportation, resulting in spills into soil and groundwater. Diesel fuel is a complex mixture, composed of about $40 \%$ n-alkanes, $40 \%$ of iso- and cycloalkanes and about $20 \%$ of aromatic hydrocarbons (Chia-Hsien et al., 2011). Among these compounds, aromatics have the highest water solubilities and affect water quality most negatively. At contaminated sites, leakage from oil storage often results in the presence of a Light-Non Aqueous Phase Liquid (L-NAPL) lens floating above water table. After a first treatment the presence of a residual NAPL phase leads to groundwater dissolved concentrations higher than legal values at most sites, thus requiring further treatment.

Presently numerous techniques are used at contaminated sites to treat these residual NAPL phases. Sparging and In Situ Chemical Oxidation (ISCO) are among the most used techniques while surfactant injection and thermal treatment are less common but their use has increased recently (Atteia et al., 2013; McGuire et al., 2006). Biodegradation is often present and can be enhanced, however it is mainly applied on the plume rather than in the source zone, leading to long treatment times (Stroo et al., 2012). The present article focuses on the 4 first techniques mentioned above and not on biodegradation.

\footnotetext{
* Corresponding author. Fondation Innovasol, 1 Allee Daguin, 33607, Pessac, France. Email address: olivier.atteia@ensegid.fr (O. Atteia)
}

To efficiently treat this kind of contamination numerous factors are important. Batch studies allow investigating several factors like the overall reaction rates or reaction types that may occur. However, the presence of a porous medium modifies the treatment techniques efficiency and thus, it is common to test treatment techniques with column experiments. Columns filled with calibrated sand allow testing the effect of the porous medium without disturbance of preferential flow. Although column results will not directly be applicable to field scale, treatment efficiencies at a heterogeneous site are always lower than in controlled columns. The optimization of the treatment process through column studies is thus an important prerequisite.

One of the most studied techniques in columns is surfactant injection (Mao et al., 2015). Most of the tests were conducted on chlorinated solvents for which very high increases in solubility can be reached. In some studies a removal of $99 \%$ of the pollutant was reached (Pennell et al., 1994), while for others a removal of only $40-60 \%$ was reached, without any clear explanation of these differences (Khalladi et al., 2009; Lee et al., 2001).

Concerning sparging, several studies were conducted on 2D vertical laboratory pilots (Reddy and Adams, 2000; Rogers and Ong, 2000; Semer et al., 1998) but few on columns. The objective of these 2D pilots was to explore the gas preferential pathways, which significantly reduce the treatment efficiency (Braida and Ong, 2001). At the column scale this effect has also been clearly demonstrated through X-ray scanning (Chen et al., 1996) and has been successfully mod- 
eled through a semi-empirical approach including a frequency of air tubes (Braida and Ong, 2000).

For chemical oxidation, BTEX high removal rates were shown through batch experiments (Anhua et al., 2014; Crimi and Taylor, 2007). In columns, removal of Polycyclic Aromatic Hydrocarbons (PAH) by Fenton or persulfate was quite low (Lemaire et al., 2013). Fenton's reagent was an efficient oxidant in batches (Crimi and Taylor, 2007; Kim and Lee, 2012) but also in Diesel contaminated columns (Stuart et al., 2001). The main issue about Fenton injection on field sites is the explosion hazard of the mixture. To face this issue some authors use pulsed injection (Watts et al., 2014) or use peroxide alone at places where iron is present in the solid phase (Ravikumar and Gurol, 1994). Permanganate is widely used for chlorinated solvents but is not efficient on benzene (Crimi and Taylor, 2007). Persulfate has been used more recently (Siegrist et al., 2011). It has the advantage of being stable for several days or weeks in the medium and can thus easily reach places distant from the injection area. Ozone has been used only at few contaminated sites, but has been studied at the column scale (Alcantara-gardu, 2008; Choi et al., 2002).

Very few studies reported the use of thermal remediation in columns (Falciglia et al., 2011; Zhao et al., 2014), but high removal efficiency was reported in the field (McGuire et al., 2006).

This short literature review revealed that almost no study compared several techniques on columns and that most of the results were on chlorinated solvents while BTEX remain an important challenge at several sites. This study has thus two major objectives:

- To compare, for the first time, four techniques using the same medium and contamination, in order to find out the best parameters to reach high efficiency.

- To determine the physical and chemical factors that may limit the efficiency of the investigated treatment techniques in a homogeneous porous medium.

It was chosen to investigate challenging conditions where a successful treatment was possible but difficult to achieve. This is why sand with an average hydraulic conductivity of $10^{-4} \mathrm{~m} \mathrm{~s}^{-1}$ was selected and water velocities close to field conditions were used. Secondly, if the technique was not sensitive to the nature of the contaminant in a group of substances, the least toxic substance was chosen for safety reasons. Thirdly, a range of contaminants were used to explore the potential limits of each technique.

\section{Materials and methods}

\subsection{Chemicals}

The following contaminants (pure grade) were used: n-decane $\left(\mathrm{C}_{10} \mathrm{H}_{22}\right.$, Fisher, Strasbourg, France), menthol $\left(\mathrm{C}_{10} \mathrm{H}_{20} \mathrm{O}\right.$, Fisher, Strasbourg, France), benzene $\left(\mathrm{C}_{6} \mathrm{H}_{6}\right.$, Baker, Rennes, France), toluene $\left(\mathrm{C}_{7} \mathrm{H}_{8}, 98 \%\right.$ Fisher, France $)$, o-xylene $\left(\mathrm{C}_{8} \mathrm{H}_{10}, 98 \%\right.$ Fisher, Strasbourg, France). Three different contaminant mixtures were used:

- a 1:1 (v) n-decane and menthol mixture.

- a 1:1:1 (v) benzene, toluene and o-xylene mixture.

- a 1:1 (v) n-decane and toluene mixture.

The physical and chemical properties of these pollutants are described in Table SI1.

\subsection{Column set up}

Stainless steel columns used in the experiments have a diameter of $3.9 \mathrm{~cm}$, effective length of $11.2 \mathrm{~cm}$. Each column was carefully filled with calibrated sand (MI 31, Sibelco, Authenay, France) of $10^{-4} \mathrm{~m} \mathrm{~s}^{-1}$ hydraulic conductivity and packed in order to reach the same pore volume (PV, determined by mass balance) of $49.5 \mathrm{~mL}$. A part of the columns used for thermal treatment were filled with a mixture of the calibrated sand and clay (Kaolinite, Sibelco, Authenay, France) leading to a measured hydraulic conductivity equal to $10^{-5}$ and $10^{-6} \mathrm{~m} \mathrm{~s}^{-1}$ for mixtures containing 10 and $20 \%$ of clay (in mass), respectively.

The L-NAPL saturation in the porous media was fixed to $6 \%$. For this purpose, sand, water, and pollutants were mixed in a beaker to obtain a homogeneous mixture. This homogeneity was validated by multiple point sampling in blank columns. For volatile products the mixing was achieved at $4{ }^{\circ} \mathrm{C}$ and as rapidly as possible (a few minutes) to limit volatilization.

\subsection{Treatments}

The applied treatments were defined after a detailed literature review, given in section 4 . Concerning oxidation, despite the numerous papers in literature, several experiments were first conducted in batch in order to select the most efficient oxidant and the best concentrations, specifically for persulfate. Tween ${ }^{\circledR} 80$ (Aldrich, Bar-le-Duc, France) was selected as surfactant because of its high dissolution capacity and low toxicity. For sparging, as presented in introduction, preferential gas flow is the main issue, conducting to choose low air flow rates. For thermal treatment, the temperature was selected according to the vapor pressure of the used contaminants (see details in section 4).

The treatments are described in Table 1 and three repetitions were conducted for each treatment.

Oxidants and surfactants were injected in a liquid form with a peristaltic pump at ratio given in Table 1. For persulfate injection two frequencies were used: 1 injection per week during four weeks and 1 injection per month during two months. During the inactive time, the injected volume of persulfate simply stayed in the column at room temperature. The added persulfate was in large excess for the first test OPS1 $(0.92 \mathrm{~mol}$ per column for $0.016 \mathrm{~mol}$ of contaminants or a stoichiometric requirement of $0.49 \mathrm{~mol}$ ) to avoid persulfate limitation during the experiment, and at stoichiometry for the OPS2 test.

For all experiments using Fenton, 2 PV of Fenton solutions were injected each day during 7 days. During the first experiment the $\mathrm{H}_{2} \mathrm{O}_{2}$ and iron sulfate solutions, components of the Fenton reagent, were injected at a flow rate of $1 \mathrm{~mL} \mathrm{~min}^{-1}$ in three periods of $1 \mathrm{~h}: 15 \mathrm{~min}$ $\mathrm{H}_{2} \mathrm{O}_{2}, 15$ min iron and 30 min without injection. In the second set of experiments, the injected volumes were the same. The time slots were changed and lasted 3 min each and were separated by 9 min without injection. The injection flow rate was set up at $1.25 \mathrm{~mL} \mathrm{~min}^{-1}$ in order to reach the same total injection time of $3 \mathrm{~h}$ per day (Fig. S1). The total injected amount of $\mathrm{H}_{2} \mathrm{O}_{2}$ was in excess ( $1.3 \mathrm{~mol}$ for a demand of $0.49 \mathrm{~mol}$, as for persulfate experiment)Ozone was injected into columns using an ozone generator (BMT, $802 \mathrm{~N}$ model) with a fixed ozone rate production which resulted in the injection of $130 \mathrm{PV}$ of air and $10.5 \mathrm{~g}$ of ozone during the 7 days of the experiment.

Air injection for sparging was performed with a syringe pump and for ozone the ozone-air mixture was directly injected with the ozone generator. Air injection was performed at a continuous low flow rate of $1 \mathrm{~mL} \mathrm{~min}^{-1}$ for a total of $2 \mathrm{PV}(98 \mathrm{~mL})$ per day. The overall treat- 
Table 1

Description of the treatments applied to the columns.

\begin{tabular}{|c|c|c|c|c|c|c|}
\hline Category & Type & Contaminant mixture & Name & Concentra-tions of agent & Total injected volume & Frequency of injections \\
\hline Oxidation & activated persulfate & Decane/menthol & $\begin{array}{l}\text { OPS1 } \\
\text { OPS2 }\end{array}$ & $\begin{array}{l}{\left[\mathrm{Na}_{2} \mathrm{~S}_{2} \mathrm{O}_{8}\right]=550 \mathrm{~g} \mathrm{~L}^{-1}} \\
{\left[\mathrm{FeSO}_{4}\right]=27.8 \mathrm{~g} \mathrm{~L}^{-1}}\end{array}$ & $\begin{array}{l}8 \mathrm{PV} \\
4 \mathrm{PV}\end{array}$ & $\begin{array}{l}1 / \text { week } \\
1 / \text { month }\end{array}$ \\
\hline Oxidation & $\begin{array}{l}\text { Fenton long slots } \\
\text { Fenton short slots }\end{array}$ & $\begin{array}{l}\text { Decane/menthol } \\
\text { Decane/menthol }\end{array}$ & $\begin{array}{l}\text { OF1 } \\
\text { OF2 }\end{array}$ & $\begin{array}{l}{\left[\mathrm{H}_{2} \mathrm{O}_{2}\right]=63 \mathrm{~g} \mathrm{~L}^{-1}} \\
{\left[\mathrm{FeSO}_{4}\right]=3.15 \mathrm{~g} \mathrm{~L}^{-1}}\end{array}$ & $14 \mathrm{PV}$ & $2 \mathrm{PV} /$ day \\
\hline Oxidation & Ozone & $\begin{array}{l}\text { Decane/menthol } \\
\text { BTX }\end{array}$ & $\begin{array}{l}\mathrm{OO} 1 \\
\mathrm{OO} 2\end{array}$ & $10.5 \mathrm{~g}$ & $130 \mathrm{PV}$ & continuous \\
\hline Surfactant flushing & Tween ${ }^{(\mathbb{R}} 80$ & $\begin{array}{l}\text { Decane/menthol } \\
\text { Decane/toluene }\end{array}$ & $\begin{array}{l}\mathrm{Su} 1 \\
\mathrm{Su} 2\end{array}$ & $10 \mathrm{CMC}$ & $40 \mathrm{PV}$ & 2 PV/day \\
\hline Sparging & Air & $\begin{array}{l}\text { Decane/menthol } \\
\text { BTX }\end{array}$ & $\begin{array}{l}\text { Sp1 } \\
\text { Sp2 }\end{array}$ & & $14 \mathrm{PV}$ & $2 \mathrm{PV} /$ day \\
\hline Thermal treatment & $\begin{array}{l}\text { sand } \\
\text { sand } \\
\text { Sand }+10 \% \text { clay } \\
\text { Sand }+20 \% \text { clay }\end{array}$ & $\begin{array}{l}\text { Decane/menthol } \\
\text { BTX } \\
\text { BTX } \\
\text { BTX }\end{array}$ & $\begin{array}{l}\text { Th1 } \\
\text { Th2 } \\
\text { Th3 } \\
\text { Th4 }\end{array}$ & & & \\
\hline
\end{tabular}

ment lasted 7 days for each type of columns. The gas phase was recovered with Tedlar bags at the column outlet.

Concerning surfactant, $40 \mathrm{PV}$ of a Tween $^{\circledR} 80$ solution at $150 \mathrm{mg} \mathrm{L}^{-1}$ ( 10 CMC, Critical Micelle Concentration) were injected at a rate of $2 \mathrm{PV}$ per day for each set of experiments. The solution was injected daily in sequences of $15 \mathrm{~min}$ of continuous flow each hour during $6 \mathrm{~h}$.

For thermal treatment the columns were kept in an oven with a Tedlar bag at the outlet (at room temperature).

\subsection{Analysis}

The recovery of contaminants in solutions containing surfactant collected at the column outlets was done by first adding $40 \mathrm{~mL} \mathrm{~L}^{-1}$ of methanol into the solution to destabilize the contaminant-surfactant bond. Then, decane was added for the contaminant extraction. The measured efficiency of this extraction procedure was equal to $95 \%$.

The remaining mass of pollutants was analyzed from sand extraction after treatment. For this purpose three aliquots of $20 \mathrm{~g}$ of soil were sampled after mixing the soil of each column. These aliquots were placed in $75 \mathrm{~mL}$ of methanol and shaken during $24 \mathrm{~h}$ (room temperature, $20 \mathrm{rpm}$ ). A volume of $2 \mathrm{~mL}$ of the supernatant was then sampled for analysis.

Three control columns were realized with the same procedure, and were directly dismounted to analyze the pollutant content. These controls showed recovery yields between 99 and $101 \%$ with 5\% error (as standard deviation divided by the mean).

\section{Results and discussion}

\subsection{Oxidation}

The first experiments were conducted through an injection of one PV of activated persulfate per week, leading to a total of $4 \mathrm{PV}$ injected (PS1). These experiments revealed a removal close to $10 \%$ for the decane and $95 \%$ for the menthol that were present in the NAPL phase. The same study was performed with one injection per month with the same concentrations of persulfate and thus only 2 PV (PS2). In that case, the removal of decane was close to $55 \%$ and menthol reached a removal of $95 \%$ of the initial amount.

For Fenton treatment slots of $\mathrm{H}_{2} \mathrm{O}_{2}$ were followed by injection of the iron solution (Table 1). The experiments performed with long slots of 15 min between the injection of iron sulfate solution and hy- drogen peroxide (OF1) did not remove any decane and lead to a removal of $83 \%$ of the initial menthol. The experiments conducted with a short slot of 3 min (OF2) resulted in a better mixing of $\mathrm{H}_{2} \mathrm{O}_{2}$ with the activating agent $\mathrm{Fe}$ and removed $44 \%$ of decane and more than $90 \%$ of the initial menthol.

In a first approach the analysis of the oxidation tests revealed that the most important factor was the aqueous solubility of the contaminant (Fig. 1). This result seemed to be independent of the oxidant used. This can be explained by the slow dissolution of the NAPL phase that can be a limiting factor of the oxidant efficiency. This is confirmed by batch experiments with dissolved compounds under the same conditions that showed no limitations on the reaction kinetics.

Using all literature data on column experiments (data given in $\mathrm{SI}$ ) there was no clear correlation between the solubility and the removal (Fig. 2). In this figure several column experiments are compared by differentiating the type of oxidants, with no clear efficiency pattern. In these literature results, the effect of the solubility may be masked by two other elements: a limitation by kinetics, or the use of dissolved sources. The only group for which enough experiments were provided was PAH which have very low water solubility (between 0 and $40 \mathrm{mg} \mathrm{L}^{-1}$ ). For this group the removal efficiency can reach values higher than $80 \%$ only when using ozone.

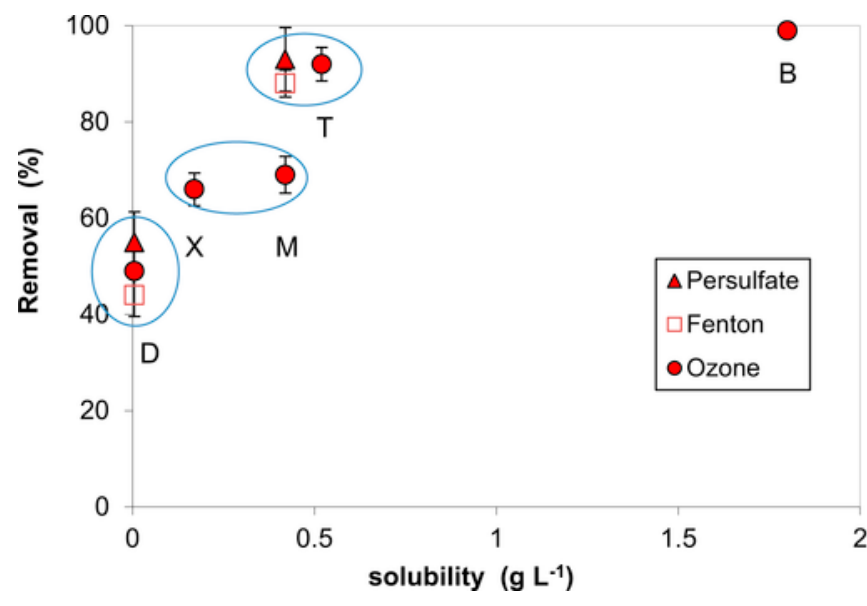

Fig. 1. Oxidation removal efficiency related to the solubility of the substance (this study), error bars represent one standard deviation calculated from three replicates and each circle a group of non-statistically different points. Letters show the substance (B: benzene, T: toluene, M: menthol, X: xylene, D: decane). 


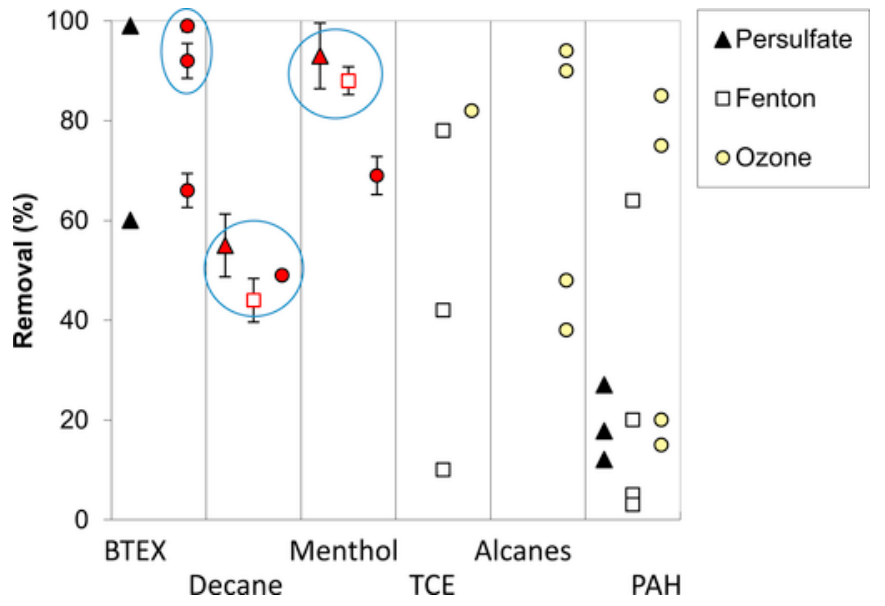

Fig. 2. Efficiencies of oxidation differentiated by type of contaminant and oxidant (points measured in this study are in red), error bars represent one standard deviation calculated from three replicates and each circle a group of non-statistically different points. (For interpretation of the references to colour in this figure legend, the reader is referred to the web version of this article.)

\subsection{Surfactants}

There is no theoretical way to determine the value of the solubility of one substance in presence of a surfactant; which must be determined experimentally (Lee et al., 2001). The measured water solubility of menthol was equal to $450 \mathrm{mg} \mathrm{L}^{-1}$ at $20^{\circ} \mathrm{C}$ while in presence of the surfactant, the solubility did not change. The same test on toluene with Tween ${ }^{\circledR} 80$ showed a measured water toluene solubility rise from $530 \mathrm{mg} \mathrm{L}^{-1}-1250 \mathrm{mg} \mathrm{L}^{-1}$ at $20^{\circ} \mathrm{C}$. The overall recovery of menthol was $30 \%$, while the one of toluene was close to $95 \%$.

The transient recovery of the contaminants at the column outlet is shown in Fig. S2. The concentrations of menthol were almost stable during the whole recovery at a value close to $200 \mathrm{mg} \mathrm{L}^{-1}$ while the solubility is equal to $450 \mathrm{mg} \mathrm{L}^{-1}$. For toluene the concentration was close to $650 \mathrm{mg} \mathrm{L}^{-1}$ during the first eight days, with a peak of $2.5 \mathrm{~g} \mathrm{~L}^{-1}$ which may be due to some mobilization of toluene as a NAPL. Then, the toluene concentration decreased and remained around $300 \mathrm{mg} \mathrm{L}^{-1}$. By contrast, and as could be expected based on the solubility, the recovery of decane was very low (concentration below $1 \mathrm{mg} \mathrm{L}^{-1}$ ).

There was no decrease in removal rate after day 11 , which suggests that a continuation of the experiment shall lead to the removal of all the soluble compounds (toluene and menthol). These data also show that the concentrations in solution were close to the theoretical values calculated using Raoult's law based on the solubility of each compound, as suggested by McCray and Brusseau (1998).

Fig. 3 shows the removal efficiency as a function of the solubility of the pollutant in presence of surfactant, including experimental results and literature data (data in SI). The trend shows that for solubilities in surfactant lower than $10 \mathrm{~g} \mathrm{~L}^{-1}$, the efficiency decreases below $90 \%$, but there is no clear correlation. Below this value some high efficiencies may exist, when using Tween ${ }^{\circledR} 80$ or Dowfax, but other surfactants reach lower efficiencies. Therefore the effect of the type of surfactant seems to be more important than the solubility of the pollutant as also suggested by Mao et al. (2015). The Darcy velocity or grain size did not show clear effects. This figure also shows that the results of the present study fall among the best removal efficiencies in available literature. This may be due to the use of a low Darcy velocity and Tween ${ }^{\circledR} 80$ as a surfactant.

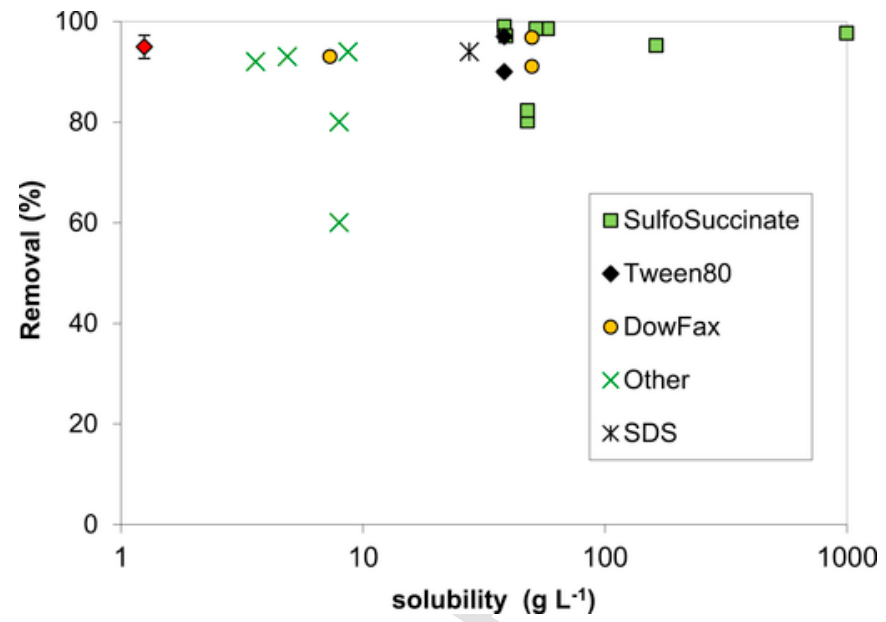

Fig. 3. Removal efficiencies compared to the solubility of the pollutant in the considered surfactant (data given in SI, the point form this study is in red with error bars equal to one standard deviation obtained from three replicates). (For interpretation of the references to colour in this figure legend, the reader is referred to the web version of this article.)

\subsection{Sparging}

For sparging, Semer and Reddy (1998) have shown that a pollutant can be removed by air sparging if its vapor pressure is higher than $670 \mathrm{~Pa}$ and if its Henry's constant is higher than $1 \mathrm{~Pa} \mathrm{~m}^{3} \mathrm{~mol}^{-1}$

Air injection into the first type of column, containing a mixture of decane/menthol (Sp1) led to a removal efficiency of 59\% for decane and $53 \%$ for menthol. Air injection in the second experiment (Sp2), removed $91 \%$ of benzene, $94 \%$ of toluene and $62 \%$ of o-xylene.

Gas sampled in Tedlar bags at the outlet of the columns contaminated by the decane/menthol (Sp1) mixture did not show the presence of volatilized pollutants. The same measurements on the columns contaminated by the mixture of BTX (Sp2) showed decreasing concentrations from benzene, to toluene and then to o-xylene (Fig. S3). As shown in Fig. S3, the measured concentrations are in the same range as theoretical ones (using Raoult's law), and thus the slowly flowing gas in sparging experiment was close to equilibrium with the residual NAPL phase. One column $\left(n^{\circ} 1\right)$ showed concentrations much lower than the others may be due to preferential flow paths.

To compare the results of this study with literature, the vapor pressure of the contaminant was used firstly, as the main differentiating parameter. Fig. 4 shows that the overall efficiency increased from $50 \%$ for very low vapor pressure of $8 \mathrm{~Pa}$ (Menthol) to $100 \%$ for the common volatile products (benzene, TCE) that have vapor pressure higher than $1 \mathrm{kPa}\left(\right.$ at $\left.20^{\circ} \mathrm{C}\right)$. However, even for volatile products the removal yield can vary from 60 to $100 \%$.

As shown in columns or in 2D pilot scale experiments (Braida and Ong, 2000, 2001), the major limitation of the air sparging technique is the inter-distance of the gas channels in the medium. Fig. 4 shows that for volatile products the efficiency seems to be higher in coarse sand. However, the present results show a high removal efficiency in medium sand. This may be due to a significant difference: the gas was injected at very low flow rate (2 PV/day) and in a pulsed way. This approach allowed reaching equilibrium concentrations in the gas phase, while generally in other experiments injection rates were much higher and concentrations were 10-100 times lower than those at equilibrium (Braida and Ong, 2000; Semer et al., 1998). However this will be difficult to apply in the field where the radius of influence 


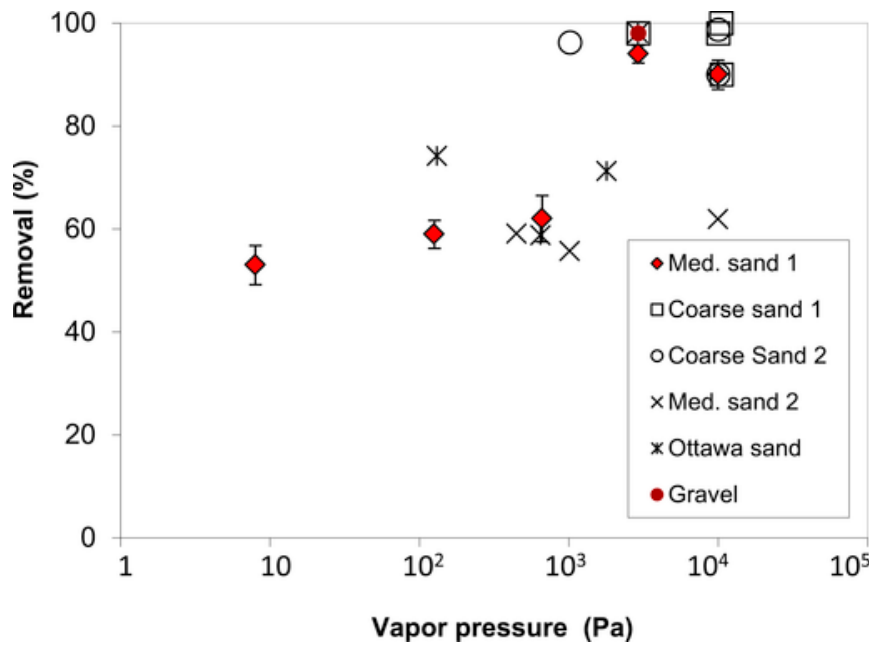

Fig. 4. Removal efficiencies during sparging related to the vapor pressure of the compound of interest (results from this study correspond to medium sand 1, other data and references in SI). The points of this study are in red with errors bars that equal one standard deviation obtained from three replicates. (For interpretation of the references to colour in this figure legend, the reader is referred to the web version of this article.)

of an air sparging well is largely dependent on the gas flow rate (Reddy et al., 1995).

\subsection{Ozone sparging}

In the columns contaminated with the decane/menthol mixture (OO1), the ozone sparging removed $50 \%$ of decane and $70 \%$ of menthol. The same experiment performed in columns contaminated with a BTX mixture (OO2) removed $99 \%$ of benzene, $94 \%$ of toluene and $65 \%$ of o-xylene.

Analyzes realized on the gas sampled in Tedlar bags connected to the outlet of the columns contaminated with the decane/menthol mixture did not show volatilized pollutants. Columns contaminated with the BTX mixture showed high concentrations of benzene and toluene, and low concentrations of o-xylene in Tedlar bags (Fig S4). The measured concentrations of benzene and toluene were lower than the equilibrium one suggesting some degradation of these substances by ozone. Concerning o-xylene the concentrations are highly variable and although looking higher than in sparging tests, are not very different from the equilibrium ones. This suggests an absence of oxidation of o-xylene with the use of ozone, while ozone can generally oxidize xylenes.

Few studies presented results of ozone sparging in saturated soil columns. Removal efficiencies reached values higher than $80 \%$ for some PAH experiments (O'Mahony et al., 2006), which was not the case for persulfate, Fenton being intermediate (Fig. 2). In the present experiments, benzene and toluene reached also high removal efficiencies, although these may arise from a mixture of sparging and oxidation. Among the few papers studying it, the water content showed contradictory effects, increasing the efficiency for some experiments (Choi et al., 2002) and decreasing it in others (Yu et al., 2007).

\subsection{Low temperature thermal treatment}

Thermal treatment at $80^{\circ} \mathrm{C}$ applied during 7 days on columns filled with sand contaminated with the decane/menthol mixture (Th1) removed only $35 \%$ of decane and $15 \%$ of menthol. The same treatment applied to columns contaminated with BTX (Th2) mixture removed all pollutants $(100 \%)$.
Thermal treatment at $80{ }^{\circ} \mathrm{C}$ applied on a mixture of sand and clay (90/10) polluted by BTX, removed $95 \%$ of benzene, $86.5 \%$ of toluene and $70.5 \%$ of o-xylene. The same experiment conducted in a porous media with a mixture of sand and clay $(80 / 20)$, removed $90 \%$ of benzene, $80 \%$ of toluene and $71.5 \%$ of o-xylene.

Very few studies of thermal treatment in columns exist in the literature. In absence of water flow, the theory of pollutant removal in porous medium is now well established through the co-boiling process (Zhao et al., 2014). In presence of water and a mixture of pollutants in a NAPL phase the vapor pressure of all gases together reach a total pressure higher than the atmospheric pressure leading to the build-up of micro-bubbles, that then flow vertically into the porous medium (Burghardt and Kueper, 2008).

For the few studies existing in literature, it is shown that when the co-boiling temperature of the mixture is reached then the removal efficiency is often very close to $100 \%$. It can be seen in Fig. 5 that the only situation where much lower removal efficiencies were observed was for sparingly volatile substances like decane or menthol $\left(\mathrm{P}_{\text {vap }}<500 \mathrm{~Pa}\right)$ that also have boiling temperatures higher than $150{ }^{\circ} \mathrm{C}$.

One can notice that in the case of co-boiling the high removal efficiency also concerns the compounds with lower vapor pressure. The used mixture contained benzene, toluene and xylene at 1:1:1 vol ratio. At $80^{\circ} \mathrm{C}$ the sum of the vapor pressures of these compounds and water is slightly higher than $1 \mathrm{~atm}$ (1.042 atm calculating with data from Wilhoit and Zwolinski, 1971) producing micro-bubbles in the medium. When benzene is entirely removed from the medium, the sum of the partial vapor pressures becomes smaller than $1 \mathrm{~atm}$ and bubbles should not form anymore. This suggests that xylene, despite its much lower vapor pressure, is entirely removed during the period when there is still some benzene present in the medium.

Clays influence the hydraulic conductivity of the medium that decreases from $10^{-4} \mathrm{~m} \mathrm{~s}^{-1}$ to $10^{-5}$ and $10^{-6} \mathrm{~m} \mathrm{~s}^{-1}$ in presence of $10 \%$ and $20 \%$ clay content, respectively. This led to a decreasing removal rate, mainly for o-xylene that is only removed to $70 \%$ in the two clay experiments, while benzene and toluene removals decrease less (95 and $90 \%$ for benzene, 86 and $80 \%$ for toluene). It was assumed that this effect is related to the difficulties of the gas bubbles to migrate in the medium.

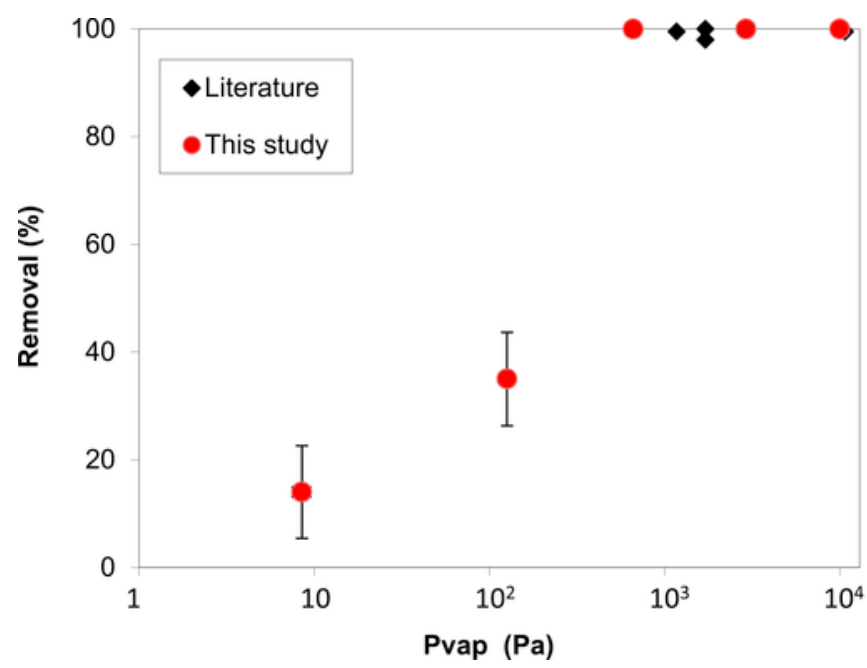

Fig. 5. Removal efficiencies of thermal treatment with vapor pressure of the considered contaminant (data and references given in SI). Errors bars represent one standard deviation. 


\subsection{Comparison of techniques}

The use of several techniques on the same columns allowed finding the best conditions to implement the different techniques to reach removal rates higher than $90 \%$. Oxidation by persulfate depended mainly on time, while oxidation by Fenton required short injection steps. For surfactant, the used molecule (here Tween ${ }^{\circledR} 80$ ) allowed to reach high removal rates. Sparging was successful through the use of low gas flow rates, and thermal treatment only required reaching the correct temperature. Concerning oxidation the results must be considered carefully as oxidation products can be produced and some toxicity may remain. Benzene has been shown to oxidize in part to hydroquinone (Fu et al., 2017), which is toxic, however less than benzene (Ahmad et al., 2000). For toluene oxidation the identified products in the Fenton reaction are benzyl alcohol, benzaldehyde and cresols (Nomiya et al., 2001) which are not carcinogens (ECHA, 2015). No hydroquinone was found (Huling et al., 2011). Under oxidation with persulfate, also bibenzyl was observed as a product (Anhua et al., 2014). Therefore the major part of the toxicity may come from benzene when present but if toluene remains its oxidation products can still provide a significant toxicity. Despite a fast oxidation rate of hydroquinone under some conditions (Elboughdiri et al., 2015) it is difficult to provide oxidation kinetics that would be valid for groundwater.

The results from the conducted experiment provide removal efficiencies in the same range than the literature data for all techniques (Figs. 1-5 and SI). They also show that, for most of the techniques, the present study reached among the highest removal efficiencies. Fig. 6 presents a comparison of the efficiency of the remediation techniques at the column scale, separating four groups of contaminants. The first group (a) includes the most soluble and volatile sub- stances (benzene, toluene, TCE), the second group (b) hydrophobic substances with lower solubility and volatility (xylenes, ethylbenzene, alcanes), the third one (c) hydrophilic substances (MTBE, phenols, menthol ...) and the fourth one (d) PAH. For each treatment a simplified histogram of the removal efficiency is presented in three categories.

The comparison of the four groups clearly shows that the highly soluble and volatile substances present the highest removal efficiencies for all techniques, as shown by Mercer and Cohen (1990). Then, the remediation efficiency decreases along the groups: xylenes and alcanes show in average slightly better efficiencies than hydrophobic substances and the most difficult to treat are PAH. It must also be emphasized that the number of potentially usable techniques decreases: for PAH only ISCO can be used, among the four proposed techniques.

Looking in detail at the results of the first group (soluble substances), differences appear between the treatment techniques. Indeed, thermal treatment has the highest efficiency leading to $100 \%$ removal for all the contaminants of this group, as also shown in the field (McGuire et al., 2006). Sparging and surfactant provide similar results: some tests revealed average removal efficiencies $(<85 \%)$, but most of them have really good removal efficiencies $(>95 \%)$. Further on, for these contaminants, ISCO revealed the lowest removal efficiencies, with most of the experiments having an efficiency below $85 \%$.

At the column scale the efficiencies among oxidation sparging and surfactant were quite similar in this study. The main objective was to identify the main limiting factors, as these factors will need to be addressed in detail to upscale the treatment at the larger pilot scale (Atteia et al., 2017).

The main factors leading to a decrease in the removal efficiency value were identified during the present study. For thermal treatment,
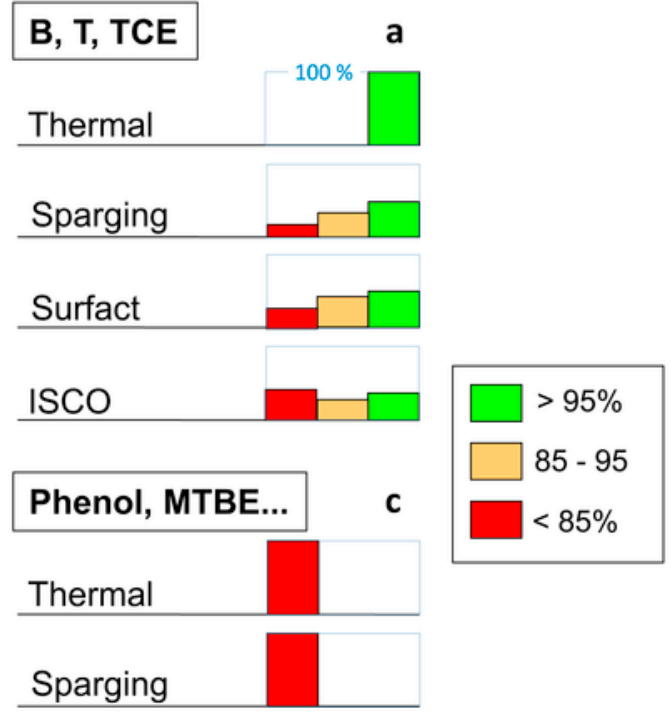

\section{PAH} d

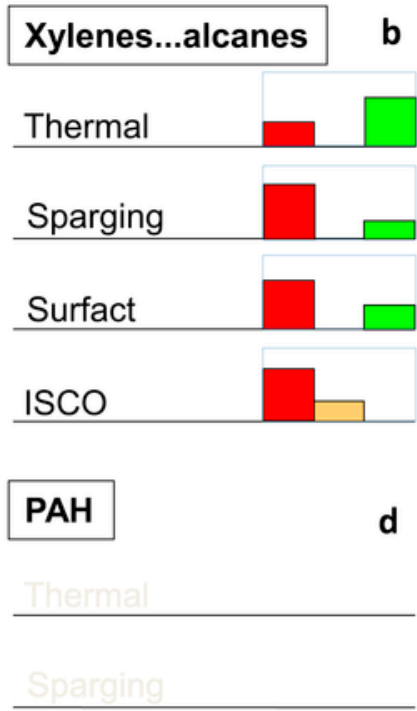

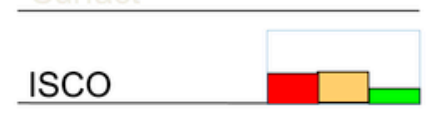

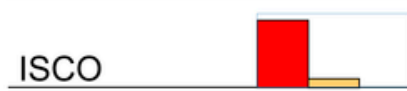

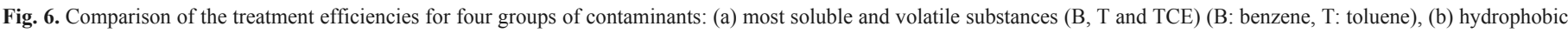

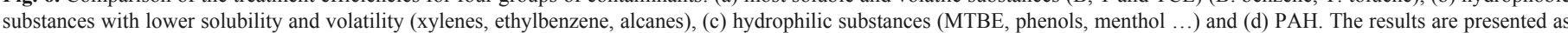

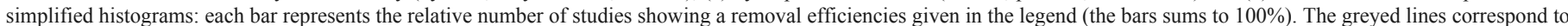
techniques that cannot be used for the given contaminant group. 
experiments showed that a decrease in hydraulic conductivity leads to a decrease of the treatment efficiency as shown in the field (Heron et al., 2005). Concerning sparging, as previously mentioned, the major limit is the potential presence of gas channels with high gas flux. For surfactant use two main factors may lead to a lower removal efficiency. First, the type of surfactant, independently of the pollutant, seems to play a significant role: Tween ${ }^{\circledR} 80$ and sulfo-succinate are the most efficient. Secondly, the solubility of the pollutant in the surfactant solution also limits the removal efficiency. Concerning ISCO, the limiting factors differ according to the used method. For Fenton reactant the main limiting factor is the amount of radicals formed which seems to be controlled by the mixing scale of hydrogen peroxide and iron. For persulfate residence time seems to be the main factor to reach high removal efficiencies.

The major mechanisms were divided into four categories:

- Access. Heat has access to everywhere, while for ISCO and surfactants incomplete dispersion and contact with NAPL blobs may limit the efficiency. For sparging the gas phase often catches only a portion of medium.

- Density: heating and sparging produce low density fluids, which may limit the action radius, an effect that is more pronounced for sparging. Surfactants are not affected by density at these concentrations. ISCO treatment with persulfate can prove to be density dependent due to the high concentrations used.

- Reaction rates: it seems that surfactants and heat have instantaneous effects. For sparging the transfer from water to air is kinetically limited. In ISCO there is a rapid loss of $\mathrm{H}_{2} \mathrm{O}_{2}$ that prevents its use without stabilizer in the field, while for persulfate the reaction is slow and adapted to typical field conditions.

\subsection{Cost analysis}

The column scale is quite small to analyze the cost differences of the techniques, therefore the results were applied to one $\mathrm{m}^{3}$, using the same amounts of contaminants and added agents. The results gathered in are quite approximate and thus only order of magnitude differences are important. The results show that, despite the need for ethanol to separate contaminant from surfactant at the treatment outlet, surfactant remains the lowest price technique; indeed the amount of added surfactant is quite small. Sparging is also a low cost technique as it requires only air injection. Fenton price remains reasonable but security requirements may largely increase that price. Persulfate price is rather high as it requires a high amount of reactant to eliminate the organics and the price per $\mathrm{kg}$ is high. Finally, the thermal treatment shows the highest price but it is the only technique that is known to remove all contaminants in the field. These costs only represent a part of the total costs and as shown by McDade et al. (2005) the total treatment costs at the site scale are very similar for these techniques, as it depends on many other factors like soil type and contaminant distribution.

\section{Conclusion}

This study was designed to determine the limitations of four treatment techniques for contaminant mixtures including BTEX. For each of the four techniques it was possible to reach removal efficiencies higher than $90 \%$. In presence of a NAPL phase, it is observed that ISCO action is mainly limited by the solubility of the product when the stoichiometry is carefully selected. For surfactant there is both effect of the solubility and the surfactant type. As previously shown, air sparging is limited by vapor pressure which may limit its effect on xylenes, or may lead to long treatment duration. Ozone sparging was not much more efficient than sparging alone as BTX concentrations remained at the column outlet. Thermal treatment is mainly limited by the medium permeability as it limits the vertical velocity of micro-bubbles.

\section{Acknowledgements}

The authors would like to thank the partner companies of the INNOVASOL Foundation which permitted the set-up of this research project. They also would like to thank the anonymous reviewers who helped to improve the quality of this paper.

\section{Appendix A. Supplementary data}

Supplementary data related to this article can be found at http://dx. doi.org/10.1016/j.chemosphere.2017.08.163.

\section{References}

Ahmad, S., Agrawal, R., Agrawal, D.K., Rao, G.S., 2000. Bioreactivity of glutathionyl hydroquinone with implications to benzene toxicity. Toxicology $150,31-39$. https: //doi.org/10.1016/S0300-483X(00)00238-9.

Alcantara-gardu, M.E., 2008. In: Experimental and Mathematical Evaluation of Trichloroethylene Removal from Saturated Soil Using Acetic Acid with Saturated Ozone, vol. 60, pp. 299-307. https://doi.org/10.1016/j.seppur.2007.09.001.

Anhua, L., Lei, Y., Zhang, H., 2014. Degradation of toluene by a selective ferrous ion activated persulfate oxidation process. Ind. Eng. Chem. Res. 53, 1033-1039. https: //doi.org/10.1021/ie402633n.

Atteia, O., Del Campo Estrada, E., Bertin, H., 2013. Soil flushing: a review of the origin of efficiency variability. Rev. Environ. Sci. Biotechnol. 12, 379-389. https:// doi.org/10.1007/s11157-013-9316-0.

Atteia, O., Jousse, F., Cohen, G., Höhener, P., 2017. Comparison of residual NAPL source removal techniques in 3D metric scale experiments. J. Contam. Hydrol. https://doi.org/10.1016/j.jconhyd.2017.04.006.

Braida, W., Ong, S.K., 2000. Modeling of air sparging of VOC-contaminated soil columns. J. Contam. Hydrol. 41, 385-402. https://doi.org/10.1016/ S0169-7722(99)00075-3

Braida, W.J., Ong, S.K., 2001. Air sparging effectiveness: laboratory characterization of air-channel mass transfer zone for VOC volatilization. J. Hazard. Mater. 87, 241-258. https://doi.org/10.1016/S0304-3894(01)00287-4.

Burghardt, J.M., Kueper, B.H., 2008. Laboratory study evaluating heating of tetrachloroethylene impacted soil. Ground Water Monit. Remed. 28, 95-106. https:// doi.org/10.1111/j.1745-6592.2008.00214.x.

Chen, M.-R., Hinkley, R.E., Killough, J.E., 1996. Computed tomography imaging of air sparging in porous media. Water Resour. Res. 32, 3013-3024. https://doi.org/ 10.1029/96WR01136.

Chia-Hsien, Y., Chen, K.-F., Kao, C.-M., Liang, S.-H., Chen, T.-Y., 2011. Application of persulfate to remediate petroleum hydrocarbon-contaminated soil: feasibility and comparison with common oxidants. J. Hazard. Mater. 186, 2097-2102. https:// doi.org/10.1016/j.jhazmat.2010.12.129.

Choi, H., Lim, H.-N., Kim, J., Hwang, T.-M., Kang, J.-W., 2002. Transport characteristics of gas phase ozone in unsaturated porous media for in-situ chemical oxidation. J. Contam. Hydrol. 57, 81-98. https://doi.org/10.1016/ S0169-7722(01)00219-4

Crimi, M., Taylor, J., 2007. Experimental evaluation of catalyzed hydrogen peroxide and sodium persulfate for destruction of BTEX contaminants. Soil Sediment. Contam. 16, 29-45. https://doi.org/10.1080/15320380601077792.

ECHA, 2015. European Chemical Agency, [WWW Document]. URL https://echa. europa.eu/information-on-chemicals.

Elboughdiri, N., Mahjoubi, A., Shawabkeh, A., 2015. Optimization of the degradation of hydroquinone, resorcinol and catechol using response surface methodology. Adv. Chem. Eng. Sci. 5, 111-120.

Falciglia, P.P., Giustra, M.G., Vagliasindi, F.G.A., 2011. Low-temperature thermal desorption of diesel polluted soil: influence of temperature and soil texture on contaminant removal kinetics. J. Hazard. Mater. 185, 392-400. https://doi.org/10. 1016/j.jhazmat.2010.09.046.

Fu, X., Gu, X., Lu, S., Sharma, V.K., Brusseau, M.L., Xue, Y., Danish, M., Fu, G.Y., Qiu, Z., Sui, Q., 2017. Benzene oxidation by Fe(III)-activated percarbonate: matrix-constituent effects and degradation pathways. Chem. Eng. J. 309, 22-29. https: //doi.org/10.1016/j.cej.2016.10.006.

Heron, G., Nielsen, G.S., Carroll, S., 2005. Full-scale removal of DNAPL constituents using steam-enhanced extraction and electrical resistance heating. Ground Water Monit. Remed. 25, 92-107. 
Huling, S.G., Hwang, S., Fine, D., Ko, S., 2011. Fenton-like initiation of a toluene transformation mechanism. Water Res. 45, 5334-5342. https://doi.org/10.1016/j. watres.2011.08.001.

Khalladi, R., Benhabiles, O., Bentahar, F., Moulai-Mostefa, N., 2009. Surfactant remediation of diesel fuel polluted soil. J. Hazard. Mater. 164, 1179-1184. https://doi. org/10.1016/j.jhazmat.2008.09.024.

Kim, I., Lee, M., 2012. Pilot scale feasibility study for in-situ chemical oxidation using $\mathrm{H}_{2} \mathrm{O}_{2}$ solution conjugated with biodegradation to remediate a diesel contaminated site. J. Hazard. Mater. 241-242, 173-181. https://doi.org/10.1016/j.jhazmat.2012. 09.022 .

Lee, D.H., Cody, R.D., Hoyle, E.L., 2001. Laboratory evaluation of the use of surfactants for ground water remediation and the potential for recycling them. Ground Water Monit. Remed.

Lemaire, J., Laurent, F., Leyval, C., Schwartz, C., Buès, M., Simonnot, M.-O., 2013 $\mathrm{PAH}$ oxidation in aged and spiked soils investigated by column experiments. Chemosphere 91, 406-414. https://doi.org/10.1016/j.chemosphere.2012.12.003.

Mao, X., Jiang, R., Xiao, W., Yu, J., 2015. Use of surfactants for the remediation of contaminated soils: a review. J. Hazard. Mater. 285, 419-435. https://doi.org/10. 1016/j.jhazmat.2014.12.009.

McCray, J.E., Brusseau, M.L., 1998. Cyclodextrin-enhanced in situ flushing of multiple-component immiscible organic liquid contamination at the field scale: mass removal effectiveness. Environ. Sci. Technol. 32, 1285-1293. https://doi.org/10. 1021/es970579.

McDade, J.M., McGuire, T.M., Newell, C.J., 2005. Analysis of DNAPL source-depletion costs at 36 field sites. Remed. J. 15, 9-18. https://doi.org/10.1002/rem.20039.

McGuire, T.M., McDade, J.M., Newell, C.J., 2006. Performance of DNAPL source depletion technologies at 59 chlorinated solvent-impacted sites. Ground Water Monit. Remed. 26, 73-84.

Mercer, J.W., Cohen, R.M., 1990. A review of immiscible fluids in the subsurface: properties, models, characterization and remediation. J. Contam. Hydrol. 6, $107-163$.

Nomiya, K., Hashino, K., Nemoto, Y., Watanabe, M., 2001. Oxidation of toluene and nitrobenzene with $30 \%$ aqueous hydrogen peroxide catalyzed by vanadium(V)-substituted polyoxometalates. J. Mol. Catal. A Chem. 176, 79-86. https:// doi.org/10.1016/S1381-1169(01)00258-8.

O'Mahony, M.M., Dobson, A.D.W., Barnes, J.D., Singleton, I., 2006. The use of ozone in the remediation of polycyclic aromatic hydrocarbon contaminated soil. Chemosphere 63, 307-314. https://doi.org/10.1016/j.chemosphere.2005.07.018

Pennell, K.D., Jin, M., Abriola, L.M., Pope, G.A., 1994. Surfactant enhanced remediation of soil columns contaminated by residual tetrachloroethylene. J. Contam. Hydrol. 16, 35-53. https://doi.org/10.1016/0169-7722(94)90071-X.
Ravikumar, J.X., Gurol, M.D., 1994. Chemical oxidation of chlorinated organics by hydrogen-peroxide in the presence of sand. Environ. Sci. Technol. 28, 394-400. https://doi.org/10.1021/es00052a009.

Reddy, K., Kosgi, S., Zhou, J., 1995. A review of in-situ air sparging for the remediation of VOC-contaminated satured soils and groundwater. Hazard Waste Hazard. Mater. 12, 97-118

Reddy, K.R., Adams, J.A., 2000. Effect of groundwater flow on remediation of dissolved-phase VOC contamination using air sparging. J. Hazard. Mater. 72, 147-165. https://doi.org/10.1016/S0304-3894(99)00138-7.

Rogers, S.W., Ong, S.K., 2000. Influence of porous media, airflow rate, and air channel spacing on benzene NAPL removal during air sparging. Environ. Sci. Technol. 34, 764-770. https://doi.org/10.1021/es9901112.

Semer, R., Adams, J.A., Reddy, K.R., 1998. An experimental investigation of air flow patterns in saturated soils during air sparging. Geotech. Geol. Eng. 16, 59-75. https://doi.org/10.1023/A:1008884213834.

Semer, R., Reddy, K.R., 1998. Mechanisms controlling toluene removal from saturated soils during in situ air sparging. J. Hazard. Mater. 57, 209-230. https://doi.org/10. 1016/S0304-3894(97)00095-2.

Siegrist, R.L., Crimi, M., Simpkin, T.J., 2011. In Situ Chemical Oxidation for Groundwater Remediation. Springer, New York.

Stroo, H.F., Leeson, A., Marqusee, J.A., Johnson, P.C., Ward, C.H., Kavanaugh, M.C. Sale, T.C., Newell, C.J., Pennell, K.D., Lebrón, C.A., Unger, M., 2012. Chlorinated ethene source remediation: lessons learned. Environ. Sci. Technol. 46, 6438-6447. https://doi.org/10.1021/es204714w.

Stuart, P., Wong, T., Agar, J.G., 2001. A laboratory study on the degradation of gasoline contamination using Fenton's reagent. In: 54th Canadian Geotechnical Conference. pp. 1170-1177.

Watts, R., Teel, A.L., Brown, R., Pac, T., 2014. Field Demonstration, Optimization, and Rigorous Validation of Peroxygen-based ISCO for the Remediation of Contaminated Groundwater - CHP Stabilization Protocol. ESTCP - report ER-200632.

Wilhoit, Zwolinski, 1971. Handbook of Vapour Pressure. American Petroleum Institute, Washington.

Yu, D.-Y., Kang, N., Bae, W., Banks, M.K., 2007. Characteristics in oxidative degradation by ozone for saturated hydrocarbons in soil contaminated with diesel fuel. Chemosphere 66, 799-807. https://doi.org/10.1016/j.chemosphere.2006.06.053.

Zhao, C., Mumford, K.G., Kueper, B.H., 2014. Laboratory study of non-aqueous phase liquid and water co-boiling during thermal treatment. J. Contam. Hydrol. 164, 49-58. https://doi.org/10.1016/j.jconhyd.2014.05.008. 